\title{
Pharmacokinetics of Quinapril and its Active Metabolite Quinaprilat During Continuous Ambulatory Peritoneal Dialysis
}

\author{
R. D. Swartz, MD, B. Starmann, RN, A. M. Horvath, S. C. Olson, PhD, and E. L. Posvar, MD
}

\begin{abstract}
The pharmacokinetics of quinapril, a novel angiotensin converting enzyme (ACE) inhibitor, and its active metabolite, quinaprilat, were determined following a single 20-mg oral dose of quinapril in six patients with chronic renal failure maintained on continuous ambulatory peritoneal dialysis (CAPD). Overall, quinapril was well tolerated by these CAPD patients, with mild and transient side effects, not unexpected in this clinical setting, which included pruritus, headache, nausea, and cough. Blood pressure reduction was observed in four of six patients, with onset reliably two to four hours after dosing and duration up to 48 hours, associated with quinaprilat concentrations in plasma above 90 $\mathrm{ng} / \mathrm{mL}$ for at least 33 hours postdose. Two patients experienced significant hypotension, systolic blood pressure below $90 \mathrm{~mm} \mathrm{Hg}$, which responded promptly to oral fluid administration and/or reduction in dialysate tonicity. The pharmacokinetic profile of quinapril in these CAPD patients was not significantly different from that previously observed in healthy subjects with normal renal function and in patients with moderate to severe renal dysfunction not yet requiring dialysis (RDND). The apparent elimination half-life of quinapril was approximately one hour, with negligible dialysate excretion. The pharmacokinetic profile of quinaprilat in these CAPD patients was similar to that previously observed in patients with RDND. The elimination half-life of quinaprilat was markedly prolonged when compared to that in healthy subjects and averaged 20 hours, with only a small amount of quinaprilat excreted in dialysate (mean $=2.6 \%$ of total dose). In summary, renal failure prolongs both the half-life as well as the antihypertensive effect of quinaprilat, and CAPD has little or no effect on the disposition of quinaprilat.
\end{abstract}

$\mathbf{T}$ he treatment of hypertension is an important adjunct to ongoing care in patients with chronic, irreversible renal failure who must undergo maintenance dialysis therapy. Among the treatment modalities, continuous ambulatory peritoneal dialysis (CAPD) has become more widely employed and accepted as an alternative to hemodialysis, ${ }^{1-5}$ and CAPD may actually be associated with improvement in hypertension control and reduced need for antihypertensive agents. ${ }^{1.4,6-9}$

Among the antihypertensive agents available, angiotensin converting enzyme (ACE) inhibitors are

From the Division of Nephrology, Department of Internal Medicine, University of Michigan Medical Center, Ann Arbor Michigan (Dr. Swartz and B. Starmann), and the Parke Davis Pharmaceutical Research Division, Warner-Lambert Company, Ann Arbor Michigan (A. M. Horvath and Drs. Olson and Posvar). Address for reprints: Richard D. Swartz, MD, Division of Nephrology, Department of Internal Medicine, $3914 \mathrm{~F}$ Taubman Center (Box 0364), University of Michigan Medical Center, Ann Arbor MI 48109-0364. sometimes used in patients maintained on dialysis both to control blood pressure ${ }^{\mathbf{1 0 , 1 1}}$ as well as to reduce thirst and limit voluntary fluid intake. ${ }^{12,13}$ The action of such agents is subject to alteration in the presence of renal failure, particularly when the native drug or its active metabolite is excreted primarily by the kidneys. ${ }^{14,15}$ Such is the case for the new ACE inhibitor, quinapril (CI-906; Accupril ${ }^{\circledR}$; ParkeDavis, Morris Plains, NJ), as its metabolite, quinaprilat (CI-928), is primarily responsible for the therapeutic effect and is eliminated primarily by renal excretion. ${ }^{16,17,21}$

The pharmacokinetics of quinapril and quinaprilat have been described in healthy subjects with normal renal function, ${ }^{20}$ in patients with moderate to severe renal dysfunction (creatinine clearance 9.4-25 $\mathrm{mL} / \mathrm{min}$ ) not yet requiring dialysis (RDND), and in patients maintained on regular hemodialysis. ${ }^{17}$ However, the pharmacokinetics and peritoneal elimination of quinapril and its metabolite, quinaprilat, have not been studied during CAPD. Thus, 
the current study was undertaken in order to define the pharmacokinetic profile and to gain information on the safety of this drug in patients with chronic renal failure maintained on CAPD.

\section{METHODS}

\section{Subjects}

Six patients ( 5 men and 1 woman) with chronic renal failure and creatinine clearance below $5 \mathrm{~mL} / \mathrm{min}$ who were undergoing CAPD in the University of Michigan dialysis program volunteered for this study. Patient characteristics are listed in Table I. After giving informed consent according to the protocol approved by the Institutional Review Board, patients were admitted to the Clinical Research Center.

Experimental Procedures. Following an 8-hour overnight fast, each patient received a single 20 -mg oral dose of quinapril on the morning of study day 1. Heparinized blood samples were collected serially thereafter for 72 hours, each sample immediately centrifuged and frozen at $-20^{\circ} \mathrm{C}$ for later gas chromatographic analysis to determine the respective concentrations of quinapril and quinaprilat. Urine (when available) and peritoneal dialysate were collected over 48 hours postdose and aliquots were frozen for similar analysis. Vital signs were monitored regularly after administration of quinapril, and routine meals were continued 4 hours following the quinapril dose. CAPD was performed according to the following schedule for two consecutive 24-hour periods: two 6-hour cycles, a 4-hour cycle and an overnight 8-hour cycle, with the glucose concentration of solution $\left(1.5 \%\right.$ to $4.25 \%$ Dianeal $^{\otimes}$; Baxter Healthcare Corp; Deerfield IL) adjusted to individual patient requirements for blood pressure or fluid weight control. Any adverse events were recorded and treated as necessary.

TABLE I

\begin{tabular}{|c|c|c|c|c|c|c|}
\hline \multicolumn{7}{|c|}{ Patient Characteristics } \\
\hline Patient & Age & Sex & Dry Wt (kg) & Diagnosis & Medications & CAPD (mos) \\
\hline 1 & 34 & $\mathbf{F}$ & 91.8 & Chronic GN & $\begin{array}{l}\text { Thyroid Gr } 2 \text { QD } \\
\text { Amphogel } \\
\text { Colace } \\
\text { Nephrovite QD }\end{array}$ & 33 \\
\hline 2 & 47 & $M$ & 90.9 & Chronic GN & $\begin{array}{l}\text { Procardia } 10 \text { QID } \\
\text { Alternagel } \\
\text { Benadryl } 25 \text { QD } \\
\text { Nephrovite OD }\end{array}$ & 16 \\
\hline 3 & 37 & $M$ & 76.4 & Rapidly progressive GN & $\begin{array}{l}\text { Bactrim SS QOD } \\
\text { Calcitriol .25 QD } \\
\text { CaCO3 } 2 \mathrm{gm} \text { TID } \\
\text { FeSO4 Gr } 10 \mathrm{QD} \\
\text { Multivitamin QD }\end{array}$ & 50 \\
\hline 4 & 67 & M & 75.5 & Obstructive uropathy & $\begin{array}{l}\text { Diltiazem } 30 \text { TID } \\
\text { CaCitrate Gr } 20 \text { TID } \\
\text { Calcitriol .25 QD } \\
\text { Pyridoxine } 25 \text { QD } \\
\text { Nephrovite QD } \\
\text { Metamucil } 1 \text { tbsp QD }\end{array}$ & 78 \\
\hline 5 & 39 & $\mathbf{M}$ & 64.5 & Chronic GN & $\begin{array}{l}\text { CaCO3 Gr } 20 \text { TID } \\
\text { Nephrovite QD } \\
\text { Colace QD } \\
\text { Ouinine } 200 \text { PRN }\end{array}$ & 20 \\
\hline 6 & 59 & $\mathbf{M}$ & 105.5 & Hypertension diabetes & $\begin{array}{l}\text { Propranolol } 20 \text { QID } \\
\text { Amytriptyline } 10 \text { QD } \\
\text { Calcitriol .25 QD } \\
\text { CaCO3 Gr } 20 \text { QID } \\
\text { Alucaps } 2 \text { QID } \\
\text { Aspirin Gr } 5 \text { QD }\end{array}$ & 34 \\
\hline
\end{tabular}


Drug Assay and Pharmacokinetic Methods. Plasma, urine, and dialysate quinapril and quinaprilat concentrations were determined using a sensitive and specific gas chromatographic procedure with electron capture detection. ${ }^{18}$ In brief, the method involved extracting samples through a Bond-Elut C18 column, methylating the column eluate with diazomethane, extracting the methylated products into hexane, and derivatizing with trifluoroacetic anhydride. Compounds were quantified using the peakheight ratio method with a quinapril analog serving as the internal standard. The gas chromatographic method for determining both quinapril and quinaprilat levels has been validated in dialysate $(1.5 \%$ and $4.25 \%$ glucose concentration) and in nonuremic human plasma over a range of $50-10,000 \mathrm{ng} / \mathrm{mL}$. Although rigorous validation of the assay methodology in uremic plasma was not performed, assay of actual patient samples revealed no significant interference peaks for quinapril or quinaprilat in predose dialysate, plasma or urine of uremic patients.

Maximum quinapril and quinaprilat plasma concentrations $\left(C_{\max }\right)$ and the times at which these occur $\left(t_{\max }\right)$ were determined for corresponding plasma concentration-time profiles. Areas under plasma concentration-time profiles (AUC) were de- termined using the trapezoidal rule. Apparent elimination rate constants $(z)$ were calculated as the $a b$ solute value of the slope of a least-squares linear regression of natural logarithm (ln) plasma concentration-time profile during the terminal phase. Apparent elimination half-life values $\left(t_{1 / 2}\right)$ were calculated as $\ln ^{2} / z$. Apparent plasma quinapril and quinaprilat clearances (Clp) were calculated by dividing quinapril dose by the respective quinapril or quinaprilat AUC..$^{18.19}$

\section{RESULTS}

In general, quinapril was well tolerated by CAPD patients. Four patients experienced mild transient symptoms, including itching, cough, headache, and nausea without vomiting, occurring within several hours of dosing during the first day. Two patients experienced symptomatic reduction in blood pressure which responded to oral fluid administration and/or reduction in dialysate glucose concentration.

The time courses of the mean arterial blood pressure (MAP = diastolic pressure plus one third of the difference between systolic and diastolic pressure) and plasma concentrations of quinapril and quina-

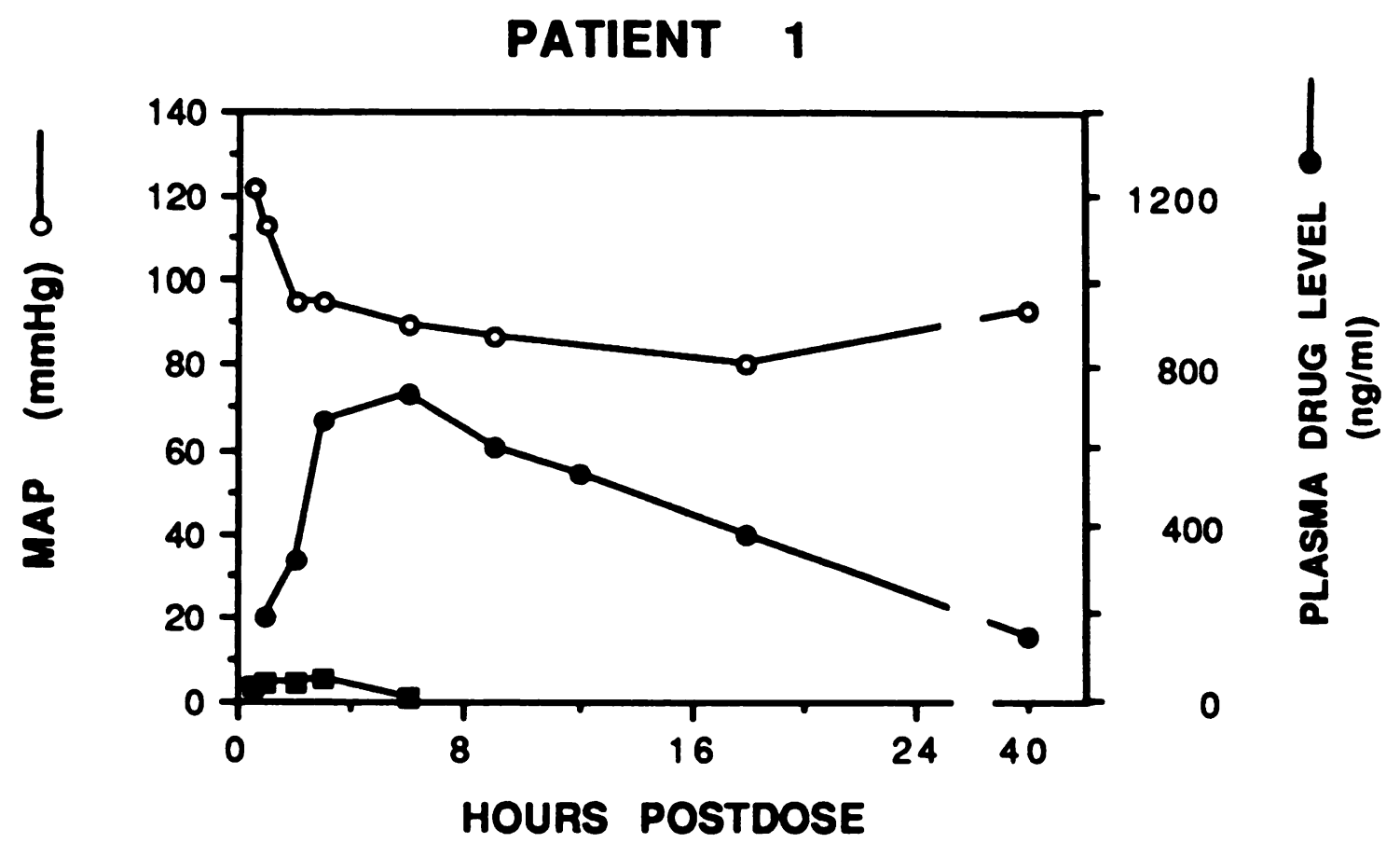

Figure 1. Time course of mean arterial pressure (MAP) and quinapril and quinaprilat plasma concentrations for Patient 1. Open circles = mean arterial pressure (MAP), closed circles = quinaprilat plasma concentration, and closed squares = quinapril concentration. 
prilat for patient 1 are presented in Figure 1. This sustained reduction in blood pressure, beginning 2 to 4 hours postdose and lasting up to 48 hours, was observed four of the six subjects. Furthermore, the reduction in MAP corresponded with the time course of quinaprilat concentration, particularly with quinaprilat concentrations persisting above 90 $\mathrm{ng} / \mathrm{mL}$ for more than 33 hours postdose. Mean changes in MAP and quinaprilat concentration for all six patients, are presented in Figure 2, showing correspondence of MAP reduction with the quinaprilat plasma concentration.

Pharmacokinetic results are presented in Table II. Peak quinapril plasma occurred at 0.5 to 3 hours postdose and ranged from 53 to $225 \mathrm{ng} / \mathrm{mL}$ (mean $=107 \pm 67 \mathrm{ng} / \mathrm{mL}$ ). Quinapril half-life averaged 1.0 \pm 0.3 hours (range $=0.7$ to $1.5 \mathrm{hr}$ ), and plasma clearance averaged $2207 \pm 1621 \mathrm{~mL} / \mathrm{min}$. Peak quinaprilat concentration occurred from 3 to 9 hours postdose and ranged from 531 to $845 \mathrm{ng} / \mathrm{mL}$ (mean $=689$ $\pm 124 \mathrm{ng} / \mathrm{ml}$ ). Quinaprilat half-life averaged 20.1 \pm 10.1 hours (range $=11.0$ to $37.4 \mathrm{hr}$ ), and plasma clearance averaged $18.9 \pm 8.4 \mathrm{~mL} / \mathrm{min}$. Quinaprilat dialysate concentrations reached less than $10 \%$ of corresponding average quinaprilat plasma concentrations during the 6-hour intervals of peritoneal equilibration. Overall peritoneal dialysis clearance of quinaprilat was less than $1 \mathrm{~mL} / \mathrm{min}$, and less than $5 \%$ of the administered quinapril was recovered as quinaprilat in peritoneal dialysate during the $\mathbf{4 8}$ hours postdose. Negligible amounts of quinaprilat were recovered in the urine of the two patients with available urine output.

\section{DISCUSSION}

The results of the present study confirm previous reports that renal failure prolongs the half-life of the quinaprilat but does not alter significantly the conversion of quinapril to quinaprilat. ${ }^{16,17.20}$ The rate and extent of quinapril absorption, the conversion of quinapril to quinaprilat as assessed by AUC, $C_{\max }$ and $t_{\max }$ values, and the rate of quinapril and quinaprilat elimination as assessed by apparent $t_{1 / 2}$, were

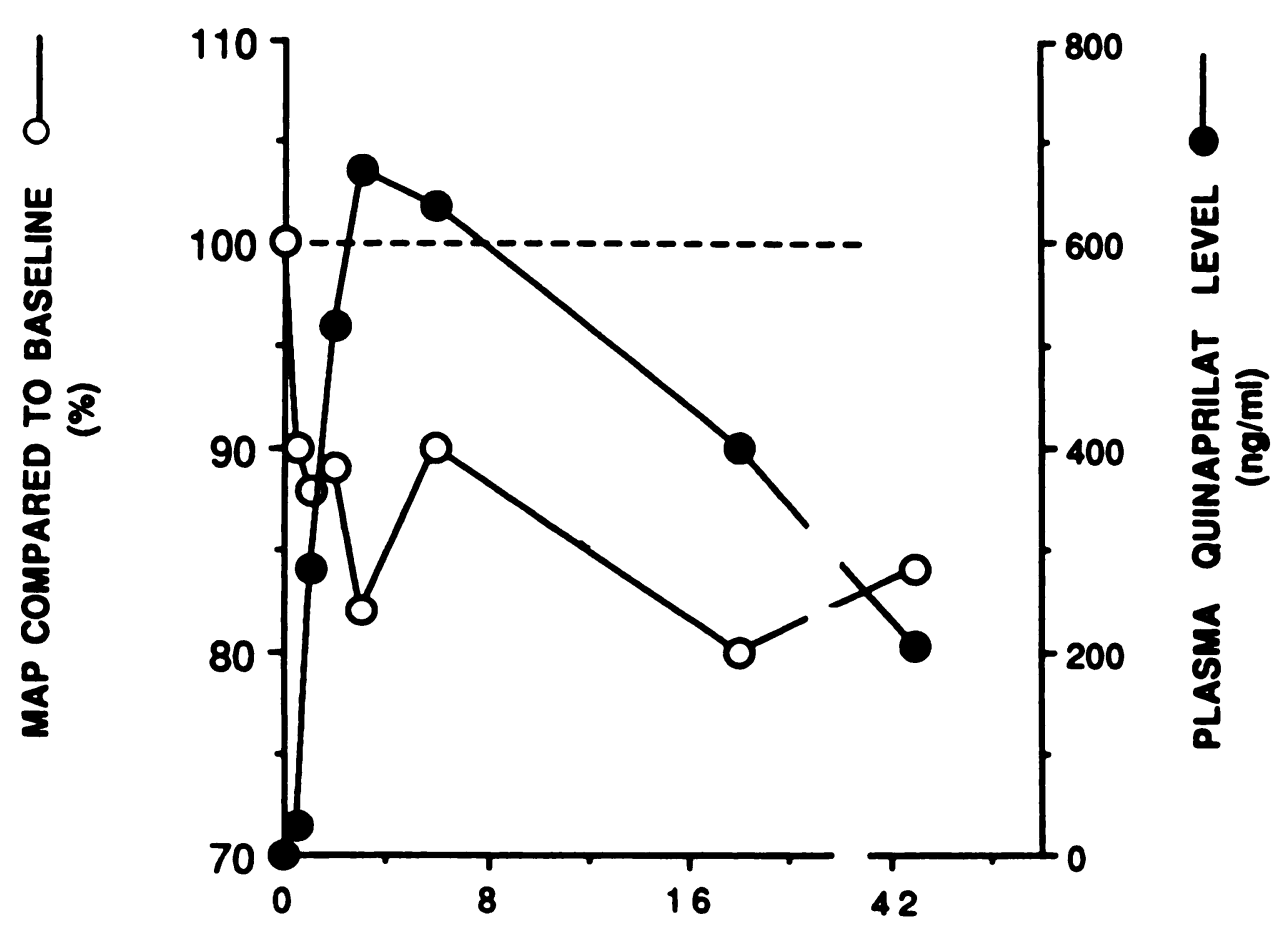

HOURS POSTDOSE

Figure 2. Time course of average percent change in mean arterial pressure (MAP) from initial baseline and average quinaprilat plasma concentration for all six patients. Open circles = mean arterial pressure (MAP) and closed circles = quinaprilat concentration. 
found not to differ markedly among patients maintained on CAPD when compared to patients with RDND, as shown in Table III.

Furthermore, CAPD appears to have little effect on quinaprilat disposition. Quinaprilat plasma clearance values observed in patients on CAPD (range $=9.1$ to $30.3 \mathrm{~mL} / \mathrm{min}$ ) are similar to those previously reported in patients with RDND (range $=12.3$ to 46.5 $\mathrm{mL} / \mathrm{min}),{ }^{17}$ and quinaprilat appeared only in small amounts in peritoneal dialysate $(0.7 \%$ to $4.1 \%$ of administered quinapril dose). This limitation in peritoneal clearance of quinaprilat may be due, in part, to the high degree of plasma protein binding, approximately $97 \%$, previously reported for quinaprilat, ${ }^{18}$ resulting in very low concentrations of free metabolite for transperitoneal diffusion.

The pharmacodynamic results of the present study are limited to only six patients; however, these results suggest that the blood pressure reduction in patients with chronic renal failure maintained on CAPD following quinapril administration may be prolonged for more than 24 hours and are associated with plasma quinaprilat levels exceeding $90 \mathrm{ng} / \mathrm{mL}$. In view of the potential for significant reduction in blood pressure in this patient population, it is important to recognize the need for caution when initiating ACE inhibitor therapy in patients with moderate or severe renal failure.

In conclusion, a single 20 -mg oral dose of quinapril was generally well tolerated by patients having chronic renal failure on CAPD, producing reductions in blood pressure that were long lasting. Quinapril and quinaprilat pharmacokinetics in patients on CAPD were similar to those observed in patients with moderate to severe renal dysfunction not yet

TABLE II

\begin{tabular}{|c|c|c|}
\hline \multicolumn{3}{|c|}{ Mean Pharmacokinetic Values for Six Patients } \\
\hline & Quinapril & Quinaprilat \\
\hline $\begin{array}{l}\text { Max Plasma Concentration } \\
\text { (ng/mL) } \\
\text { Time of Max }\end{array}$ & 107 (67) & 689 (124) \\
\hline $\begin{array}{l}\text { Concentration (hr) } \\
\text { Half-Life (hr) } \\
\text { Plasma Clearance }\end{array}$ & $\begin{array}{l}1.3(1.0) \\
1.0(0.3)\end{array}$ & $\begin{array}{l}5.4(2.5) \\
20.1(10.1)\end{array}$ \\
\hline$(\mathrm{mL} / \mathrm{min})$ & $2207(1621)$ & 19 (8.3)* \\
\hline $\begin{array}{l}\text { Dialysate Excretion } \\
\text { (\% of dose) } \\
\text { Urinary Excretion }\end{array}$ & minimal & $2.6(1.2)$ \\
\hline (\% of dose) & minimal & minimal \\
\hline
\end{tabular}

\begin{tabular}{|c|c|c|c|c|}
\hline \multicolumn{5}{|c|}{ TABLE III } \\
\hline \multicolumn{5}{|c|}{$\begin{array}{c}\text { Pharmacokinetic Parameters, Comparing CAPD } \\
\text { Patients with RDND Patients }\end{array}$} \\
\hline \multirow{2}{*}{$\begin{array}{l}\text { Pharmacokinetic } \\
\text { Parameter* }\end{array}$} & \multicolumn{2}{|c|}{ Quinapril } & \multicolumn{2}{|c|}{ Quinaprilat } \\
\hline & CAPDT & RDND† & CAPDT & RDND† \\
\hline $\begin{array}{l}C_{\max }(\mathrm{ng} / \mathrm{mL}) \\
t_{\max }(\mathrm{hr}) \\
A \cup C(\mathrm{ng} \cdot \mathrm{hr} / \mathrm{mL}) \\
\mathrm{t}_{1 / 2}(\mathrm{hr}) \\
\mathrm{z}(1 / \mathrm{hr})\end{array}$ & $\begin{array}{r}107 \\
1.3 \\
205 \\
1.01 \\
0.72\end{array}$ & $\begin{array}{r}161 \\
1.3 \\
288 \\
0.9 \\
0.79\end{array}$ & $\begin{array}{r}689 \\
5.4 \\
21283 \\
20.1 \\
0.04\end{array}$ & $\begin{array}{r}885 \\
3.6 \\
16540 \\
12.5 \\
0.06\end{array}$ \\
\hline
\end{tabular}

- $C_{\max }=$ maximum plasma concentration; $t_{\max }=$ time to $C_{\max } A U C=$ area under plasma concentration-time curve from; $t_{1 / 2}=$ apparent elimination halflife; $\mathbf{z}=$ apparent elimination rate constant.

† Mean values for six CAPD patients from present study and for seven RDND patients from references 16 and 20.

on dialysis. Thus, CAPD had little effect on the disposition of quinaprilat.

Invaluable assistance was provided by the nursing staff of the Clinical Research Center at University of Michigan Medical Center.

\section{REFERENCES}

1. Levey A, Harrington J: Continuous peritoneal dialysis for chronic renal failure. Medicine 1982;61:330-339.

2. Gokal R, King J, Bogle S, et al: Outcome in patients on continuous ambulatory peritoneal dialysis and haemodialysis: 4-year analysis of a prospective multicentre study. Lancet 1987;2:11051109.

3. Maiorca $R$, Cancarini G, Manili $L$, et al: CAPD is a first class treatment: results of an eight-year experience with a comparison of patient and method survival in CAPD and hemodialysis. Clin Nephrol 1988;30:S3-S7.

4., Nolph K, Lindblad A, Novak J: Continuous ambulatory peritoneal dialysis. N Engl J Med 1988;318:1595-1600.

5. Wolfe R, Port F, Guire K, et al: Trends in survival in hemodialysis versus CAPD patients (1980-1986). Abstract. Am Soc Nephrol 22nd Annual Meeting, December 1989.

6. Baum M, Powell D, Calvin S, et al: Continuous ambulatory peritoneal dialysis in children. N Engl J Med 1982;307:1537-1542. 7. Amair $P$, Khanna R, Leibel B, et al: Continuous ambulatory peritoneal dialysis in diabetics with end-stage renal disease. $N$ Engl J Med 1982;306:625-630.

8. Kurtz S, Wong V, Anderson C, et al: Continuous ambulatory peritoneal dialysis: three years' experience at the Mayo Clinic. Mayo Clin Proc 1983;58:633-639.

9. Wu G, Khanna R, Vas I, et al: Continuous ambulatory peritoneal dialysis: no longer experimental. Can Med Assoc J 1984;130:699-707.

10. Manintveld A, Wenting G, Schalekamp M: Does captopril lower blood pressure in anephric patients? Br Med J 1979;2:11101111. 
11. Papadimitriou $M$, Zamboulis $C$, Alexopoulos $E$, et al: Alarming hyperkalemia during captopril administration in patients on regular hemodialysis. Dial Transpl 1985;14:473-475.

12. Yamamoto $T$, Shimuzi M, Morioka $M$, et al: Role of angiotensin II in the pathogenesis of hyperdypsia in chronic renal failure. JAMA 1986;256:604-608.

13. Oldenburg B, MacDonald G, Shelley S: Controlled trial of enalapril in patients with chronic fluid overload undergoing dialysis. Br Med J 1988;296:1089-1091.

14. Campbell B, Shephard A, Elliot $H$, et al: Prolonged converting enzyme inhibition following captopril in patients with renal insufficiency. Br J Pharmacol 1982;13:755-757.

15. Duchin K, Pierides A, Heald A, et al: Elimination kinetics of captopril in patients with renal failure. Kid Int 1984;25:942-947.

16. Begg E, Bailey R, Lynn K, et al: The pharmacokinetics of ACE inhibitors in patients with renal impairment. J Hypertens 1989;7:S29-S32.
17. Blum R, Kohli R, Olson S, et al: Pharmacokinetics of quinapril $\mathrm{HCl}$ and its active metabolite, quinaprilat, in patients with endstage renal disease on chronic hemodialysis (Abstract). American College of Clinical Pharmacology, 19th Annual Meeting; Las Vegas, NV; Nov 1990.

18. Ferry J, Horvath A, Easton-Taylor M, et al: Determination of quinapril and its active metabolite in human plasma and urine by gas chromatography with electron-capture detection. J Chromatogr 1987;421:187-191.

19. Rowland M, Tozer T: Clinical Pharmacokinetics Concepts and Applications. Lea \& Febiger, Philadelphia, 1980.

20. Olson S, Horvath A, Michniewicz B, et al: The clinical pharmacokinetics of quinapril. Angiology 1989;40:351-359.

21. Kaplan H, Taylor D, Olson S, Andrews L: Quinapril-a preclinical review of the pharmacology, pharmocokinetics and toxicology. Angiology 1989;40:335-350. 